\title{
Estímulo À Produção de Ocratoxina A em Aspergillus Carbonarius e A. Niger Pelo Uso de Doses Sub-Letais de Ácido Sórbico
}

María de Jesús Alcano (I), Carlos Augusto Mallmann (I), Raquel Carine Jahn (I), Cátia Daiane Scherer (I), Évelin Francine Wigmann (I), Vivian Machado Moraes (I), Marcelo Valle Garcia (I), Marina Venturini Copetti (I)

(I) UFSM - Universidade Federal de Santa Maria (Av Roraima 1000, CCR/DTCA, Prédio 42, sala 3210. CEP 97104-900, Santa Maria-RS)

\section{Resumo}

O desenvolvimento de fungos em alimentos e a subsequente contaminação destes por micotoxinas constituem um problema de saúde pública. Dentre as micotoxinas mais importantes temos a ocratoxina A (OTA), com ação nefrotóxica e propriedades carcinogênicas. Uma estratégia para reduzir a contaminação dos alimentos por OTA é prevenir o desenvolvimento fúngico, sendo o ácido sórbico e seus sais uma importante alternativa. Entretanto, tem sido relatado que o uso deste conservante em dosagens subletais poderia ocasionar um estímulo ao metabolismo do fungo, elevando a produção de toxinas por algumas espécies. Uma vez que a eficiência antimicrobiana de ácidos orgânicos como conservante é dependente do $\mathrm{pH}$ do substrato, o objetivo desta pesquisa foi determinar a concentrações inibitória (CI) e estudar a influência de doses sub-letais de ácido sórbico sobre a produção de OTA em A. carbonarius e A. niger cultivados em caldo YES (Yeast Extract Sucrose) em diferentes valores de $\mathrm{pH}$. Utilizouse um arranjo fatorial sendo 2 fungos: A. carbonarius e A. niger, 2 valores de pH $(4,5$ e 5,0) e ácido sórbico nas concentrações: $0 ; 0,5 ; 1 ; 2 ; 4 ; 8 ; 16$; $32 \mathrm{mM}$. O experimento foi conduzido em duplicata, incubando-se por 7 dias à $25^{\circ} \mathrm{C}$ e determinando-se as concentrações inibitórias para cada isolado. Os controles e duas concentrações abaixo da CI (ou seja, 0; 25 e

\footnotetext{
Referência:

María de Jesús Alcano, Carlos Augusto Mallmann, Raquel Carine Jahn, Cátia Daiane Scherer, Évelin Francine Wigmann, Vivian Machado Moraes, Marcelo Valle Garcia, Marina Venturini Copetti.Estímulo À Produção de Ocratoxina A em Aspergillus Carbonarius e A. Niger Pelo Uso de Doses Sub-Letais de Ácido Sórbico. In: Anais do 12 Congresso Latinoamericano de Microbiologia e Higiene de Alimentos - MICROAL 2014 [= Blucher Food Science Proceedings, num.1, vol.1]. São Paulo: Editora Blucher, 2014. DOI 10.5151/foodsci-microal-066
} 
50\% da CI), foram selecionados para a análise de OTA. A quantificação da OTA foi realizada através de cromatografia líquida de alta eficiência com detector de fluorescência, separação por coluna C18 e fase móvel composta por ácido acético: acetonitrila: metanol (40: 30: 30; v/v/v), com volume de injeção de $1 \mu$ l. Observou-se diferença na concentração inibitória do ácido dependendo da espécie fúngica avaliada, sendo A. carbonarius a mais sensível. Também foi observado que a CI decresce conforme a diminui o $\mathrm{pH}$. Houve um incremento na produção de OTA em ambos os fungos testados quando em presença de $25 \%$ da CI de ácido sórbico, em ambos os $\mathrm{pH}$, e mesmo em $50 \%$ da CI os níveis de OTA foram similares aos presentes no controle negativo (sem presença de ácido sórbico). Embora haja uma demanda da população pela redução do uso de conservantes em alimentos, deve-se ter muita cautela, visto que o uso de doses antifúngicas sub-letais além de não impedir o crescimento fúngico pode elevar a produção de micotoxinas.

Palavras-Chave: micotoxina, ácido orgânico, conservante

Agência de Fomento: CNPq, FAPERGS (Bolsas de Iniciação Científica) e Fundayacucho (Bolsa de Mestrado) 